\title{
THE EFFECT OF CHANGING POSITIVE END-EXPIRATORY PRESSURES ON THE SPATIAL PATTERN OF LUNG VENTILATION IN NEWBORN RABBITS VENTILATED FROM BIRTH
}

\author{
M.L. Siew ${ }^{1}$, M.J. Kitchen ${ }^{2}$, A.B. te Pas ${ }^{3}$, M.J. Wallace ${ }^{1}$, M.S. Islam ${ }^{2}$, N. Yagi ${ }^{4}$, K. Uesugi ${ }^{4}$, S.B. Hooper ${ }^{1}$ \\ ${ }^{1}$ Ritchie Centre, Monash Institute of Medical Research, Monash University, ${ }^{2}$ School of Physics, Monash \\ University, Clayton, VIC, Australia, ${ }^{3}$ Department of Pediatrics, Division of Neonatology, Leiden University \\ Medical Centre, Leiden, The Netherlands, ${ }^{4}$ SPring-8/JASRI, Hyogo, Japan
}

Background: Positive end-expiratory pressure (PEEP) helps very preterm newborns develop functional residual capacity (FRC) and establish adequate gas exchange at birth. In the immediate newborn period, lungs commonly experience changes in PEEP, particularly when the face mask is removed and replaced. This study aimed to determine the distribution of lung ventilation at different PEEPs and in response to changes in PEEP.

Method: Rabbit pups (28dGA) were delivered by c-section and mechanically ventilated with a constant peak inflation pressure $\left(35 \mathrm{cmH}_{2} \mathrm{O}\right.$ ) and 1 of 3 strategies of PEEP: (A) $0-5-10-5-0 \mathrm{cmH}_{2} \mathrm{O}$, (B) $5-10-0-5-0 \mathrm{cmH}_{2} \mathrm{O}$ and (C) $10-5-0-10-0 \mathrm{cmH}_{2} \mathrm{O}$. Phase contrast $\mathrm{X}$-ray imaging was used to analyse the distribution of ventilation in the upper lobes $(\mathrm{U})$ vs the lower lobes $(\mathrm{L})$.

Results: At FRC, $\mathrm{U}$ was more ventilated than L. In strategy A and B, this was throughout the experiment (A 10PEEP: $70.5 \pm 2.9 \%$ vs $55.7 \pm 3.3 \%, \mathrm{p}<0.05$; B 10PEEP: $70.9 \pm 1.5 \%$ vs $56.8 \pm 2.8 \%, \mathrm{p}<0.05)$. In strategy $\mathrm{C}$, this was only at OPEEP $(29.7 \pm 3.1 \%$ vs $13.0 \pm 3.1 \%, \mathrm{p}<0.05)$. In all strategies, once total lung volume exceeded $70 \%$ of its maximum, tidal volume $\left(\mathrm{V}_{\mathrm{T}}\right)$ ventilated $\mathrm{L}$ more than $\mathrm{U}$, except in strategy $\mathrm{C}$ when PEEP increased to $10 \mathrm{cmH}_{2} \mathrm{O}$; the difference between $\mathrm{L}$ and $\mathrm{U}$ was lost $(26.8 \pm 4.7 \%$ vs $19.9 \pm 3.9 \%, \mathrm{p}>0.05)$ but recovered when PEEP returned to $0 \mathrm{cmH}_{2} \mathrm{O}(70.1 \pm 4.0 \%$ vs $53.4 \pm 3.2 \%, \mathrm{p}>0.05)$.

Conclusions: At FRC the upper lobes are more ventilated than lower lobes. $\mathrm{V}_{\mathrm{T}}$ ventilated lower lobes more than upper lobes, only once lungs were well aerated. This is not observed if ventilation began with high PEEP. 